Gynäk. Rdsch. 1985;25(suppl. 1):I-IV

\title{
Contents, Vol. 25, Supplement 1, 1985
}

Vulvovaginal Candidosis: Definition of the Disease and Its Special

Problems and Treatment in Pregnancy

Hirsch,H.A 1

Terconazole, a New Triazole Antifungal Agent

Cartwright, R.Y

6

In vitro Studies with Terconazole

Isaacson, D.M.; Foleno, B.; Tolman, E.L.; Rosenthale, M.E 12

Terconazole Cream and Suppositories: Plasma Terconazole following

Vaginal Administration

Kennedy, B.K.; Friedmann, N 26

Terconazole 0.8\% Vaginal Cream (5 Days) versus Clotrimazole 1\%

(6 Days): Efficacy and Tolerability in an Open Study

Siedentopf, H.-G

33

Advantages of a 6- to 7-Day Treatment with 40-mg Vaginal

Suppositories of Terconazole against Vaginal Candidosis:

Conclusions Drawn from a Phase II Multicentre Study in France

Delecour, M 42

Treatment of Vaginal Candidosis with Three 80-mg Terconazole

Vaginal Suppositories: Results of a Multicentre Study in France

Nahmanovici, C 52

Assessment of Clinical Efficacy and Tolerability of Terconazole

240-mg Vaginal Suppositories

Litschgi, M 59

Contents IV

Comparative Open Evaluation of Efficacy and Tolerability of

Terconazole $0.8 \%$ Cream in a 5-Day Regimen versus

Clotrimazole 100-mg Tablets in a 6-Day Regimen

Wesel, S.; Benijts, G.; Ubachs, J.M.H.; Dogniez, B 67

Comparative Double-Blind Evaluation of the Efficacy and

Tolerability of Terconazole 240-mg Suppository (1 Day) and

80-mg Suppositories (3 Days) versus Clotrimazole 200-mg

(3 Days) in Pregnant Patients with Vulvovaginal Candidosis

Goormans, E 74

One-Day Treatment of Vaginal Candidosis: Comparison of

Terconazole 240-mg Suppository with Clotrimazole 500-mg

Vaginal Tablet

Grice, G.; Spencer, R.C.; Steele, C.E.; Kinghora, G.R

Single-Day Topical Treatment of Vaginal Candidosis:

An Open Evaluation of Terconazole 240-mg Vaginal 
Suppositories versus Isoconazole Tablets $600 \mathrm{mg}$

Münnich, W.; Hiltl, B.P

90

Demonstration of Effectiveness and Tolerability of Terconazole

80-mg Vaginal Suppositories (3 Days) versus Terconazole 240-mg

Vaginal Suppositories (1 Day) versus Clotrimazole 200-mg

Vaginal Tablets (3 Days) in Non-Pregnant Women with

Vulvovaginal Candidosis

Loendersloot, E.W 99

Summary of Clinical Studies with Vaginal Formulations of

Terconazole

Martinek, G 105

Discussion 114

Summary 118

Author Index 120 